\section{O PROCESSO DE ENSINO E APRENDIZAGEM NA ALFABETIZAÇÃO: REFLEXÕES SOBRE PRÁTICAS DE LEITURA E ESCRITA}

\section{THE PROCESS OF TEACHING AND LEARNING IN LITERACY: REFLECTIONS ON READING AND WRITING PRACTICES}

Maria Lúcia dos Santos Carvalho ${ }^{1, *}$ / Elizabete Oliveira Lima ${ }^{1}$ / Dinalva de Jesus Santana Macêdo ${ }^{1}$

\begin{abstract}
RESUMO
Este artigo busca refletir sobre práticas de leitura e de escrita numa turma do terceiro ano do Ensino Fundamental de uma escola pública, para compreender os fatores que interferem na aprendizagem dos alunos. Trata-se de uma pesquisa qualitativa que utilizou de entrevista semiestruturada com a professora, grupo focal com os educandos, observação, diário reflexivo e análise documental. Os resultados apontam que a professora utiliza práticas de leitura diversificadas e contextualizadas e os educandos atribuem um valor positivo à leitura e à escrita. E apesar do PNAIC explicitar que o educando deve estar alfabetizado aos 8 anos de idade, muitas crianças com esta idade não estão alfabetizadas. Outro ponto a destacar, em relação a esse programa, é que boa parte dos educandos se encontra em defasagem idade/série. Um dos possíveis fatores que pode influenciar nesta aprendizagem, é a falta de apoio de alguns pais, talvez por não serem alfabetizados, ou pelo contexto social em que estão inseridos. Isso certamente dificulta o vínculo dos pais com a escola, o que também pode refletir na aprendizagem dos educandos. Todavia, é preciso não desconsiderar os condicionantes sociais, políticos e estruturais que interferem na vida escolar do educandos, pois o fenômeno educativo é muito complexo e extrapola os muros da escola.
\end{abstract}

Palavras Chave: Alfabetização; Letramento; Práticas de Leitura e Escrita; PNAIC.

${ }^{1}$ Departamento de Educação - Campus XII, Universidade do Estado da Bahia, Guanambi, Bahia - Brasil.

*E-mail para correspondência: maria33lucia@gmail.com

\begin{abstract}
This article seeks to reflect on reading and writing practices in a third grade class at a public elementary school to understand the factors that interfere with student learning. It is a qualitative research that used a semi-structured interview with the teacher, a focus group with the students, observation, reflective diary and documentary analysis. The results indicate that the teacher uses diverse and contextualized reading practices and the students attribute a positive value to reading and writing. And although the PNAIC states that the pupil must be literate at 8 years of age, many children of this age are not literate. Another point to emphasize, in relation to this program, is that a good part of the students is in age / grade gap. One of the possible factors that may influence this learning is the lack of support from some parents, perhaps because they are not literate, or because of the social context in which they are inserted. This certainly makes it difficult for parents to link to school, which can also reflect the learners' learning. However, it is necessary not to disregard the social, political and structural conditions that interfere in the school life of the students, since the educational phenomenon is very complex and goes beyond the walls of the school.
\end{abstract}

Keywords: Literacy; Literature; Reading and Writing Practice; PNAIC.

Submetido em: 01 de jul. 2018

Aceito em: 16 de mai. 2019

\section{INTRODUÇÃO}

O presente artigo é parte das reflexões de uma pesquisa de trabalho de conclusão do curso (tcc), que buscou analisar práticas de leitura e de escrita em uma turma do terceiro ano do ciclo de alfabetização, de uma escola pública do munícipio de Guanambi-Ba, para compreender os fatores que interferem na aprendizagem dos alunos. Assim sendo, questionou-se: De que maneira as práticas de leitura e de escrita utilizadas em sala de aula influenciam no processo de aprendizagem dos educandos?

Rev. ComCiência - jun. 2019, vol. 4, no. 4, p. 42-56/ doi: 10.36112/issn2595-1890.v4i1.p42-56 
Diante disso buscou como objetivos específicos: Descrever e analisar as práticas de leitura e escrita mobilizadas pela professora em sala de aula; Identificar a concepção da professora sobre a alfabetização e o letramento, observando a influência no processo da aprendizagem de leitura e escrita dos alunos; Identificar a perspectiva de alfabetização e letramento contemplada no PPP da escola e conhecer os sentidos que os educandos atribuem às atividades de leitura e escrita trabalhadas em sala de aula.

A temática se originou, a partir de experiências vividas pelas pesquisadoras; uma na condição de monitora no Projeto Alfabetização em Foco que é um projeto de extensão do Curso de Pedagogia da Universidade do Estado da Bahia - Campus XII por meio de atuação em sala de aula, auxiliando a professora regente nas atividades propostas em orientação aos educandos e da outra no Programa Mais Educação que é um projeto do Governo Federal em parceria com a Prefeitura Municipal no atendimento individualizado a criança com dificuldade no processo de aquisição de escrita e leitura e no Programa Institucional de Bolsa de Iniciação à Docência (PIBID) da UNEB-Campus XII por meio da docência compartilhada.

Os interlocutores foram 20 educandos de uma turma do terceiro ano do ciclo de alfabetização do Ensino Fundamental do turno vespertino e a professora da respectiva classe, totalizando 21 sujeitos. Dentre os alunos, 8 são do sexo feminino e 12 do sexo masculino, com idade que varia entre 8 a 13 anos. A professora entrevistada leciona todas disciplinas do $3^{\circ}$ ano, tem formação em Pedagogia e Especialização em Psicopedagogia e Educação Inclusiva. E também trabalha no $6^{\circ}$ ano no matutino e na EJA no noturno.
Trata-se de uma pesquisa de abordagem qualitativa, que recorreu de entrevista semiestruturada com a professora, grupo focal com os educandos, observação, diário de campo, análise do projeto político pedagógico da escola e de materiais didáticos utilizados em sala de aula.

Os dados coletados foram analisados e interpretados por meio da análise conteúdo na modalidade temática. Adotamos os seguintes procedimentos: a) Depois da transcrição fizemos a leitura e a releitura do material coletado para ter uma visão do conjunto e identificar dados importantes para o objeto de pesquisa; b) Dividimos o material em partes por categorias temáticas, estabelecendo relação com os objetivos e as questões de estudo.

Para a fundamentação teórica dialogamos com os autores: Ferreiro (2011), Ferreiro e Teberosky (1991), Kleiman (2006), Mortatti (2004), Rizzo (1990), Soares $(1985,1999,2002$, 2007, 2011), Weisz (2009), dentre outros que discutem a temática.

Conforme o Pacto Nacional de Alfabetização na Idade Certa (PNAIC), os educandos devem estar alfabetizados até o fim do ciclo de alfabetização, que corresponde até ao $3^{\text {o }}$ ano do ensino fundamental ${ }^{2}$. Como podemos destacar:

Aos oito anos de idade, as crianças precisam, portanto, ter a compreensão do funcionamento do sistema de escrita; o domínio das correspondências grafofônicas, mesmo que dominem poucas convenções ortográficas irregulares e poucas regularidades que exijam conhecimentos morfológicos mais complexos; a fluência de leitura e o domínio de estratégias de compreensão e

${ }^{2}$ Conforme a Base Nacional Comum Curricular (BNCC) da Educação Infantil e do Ensino Fundamental, toda a criança deve estar plenamente alfabetizada até o final do segundo ano do Ensino Fundamental (BRASIL, 2017). de produção de textos escritos (BRASIL, 2012a, p. 11).

Para Soares, a alfabetização é o processo em que o educando aprende a ler e a escrever e o letramento

pode ser interpretado como decorrência da necessidade de configurar e nomear comportamentos e práticas sociais na área da leitura e da escrita que ultrapassem o domínio do sistema alfabético e ortográfico, nível de aprendizagem da língua escrita perseguido, tradicionalmente, pelo processo de alfabetização (SOARES, 2011 p. 96).

Nessa perspectiva, o letramento não é só aprender a ler e a escrever, é preciso compreender qual a função da leitura e da escrita nas práticas sociais. No mesmo sentido Mortatti (2004) reforça o conceito de letramento.

Letramento está diretamente relacionado com a língua escrita e seu lugar, suas funções e seus usos nas sociedades letradas, ou, mais especificamente, grafocêntricas, isto e, sociedades organizadas em torno de um sistema de escrita e em que esta, sobretudo por meio do texto escrito e impresso, assume importância central na vida das pessoas e em suas relações com os outros e com o mundo em que vivem (MORTATTI, 2004, p.99).

Dessa forma, na perspectiva das autoras, os professores alfabetizadores devem trabalhar de forma que os dois processos ocorram, pois alfabetização e letramento estão interligados e não podem ser dissociados.

Aprender a ler e escrever é um processo de construção identitárias para os alunos de grupos dominados, mais pobres, de tradição oral, porque envolve a aprendizagem de práticas sociais de outros grupos que são, em sua maioria, alheios aos seus interesses, modos de ação e modos de falar. Daí a relevância 
de focalizarem-se os aspectos políticos do trabalho do professor que o conceito de mediador apaga e o conceito de agente de letramento ressalta (KLEIMAN, 2006, p. 422).

Por isso, ao abordar o aprendizado do educando teremos que caminhar pelo processo de Alfabetização e Letramento para compreender como se dá as relações de ensino/aprendizagem.

Este texto está organizado da seguinte maneira: No primeiro momento, discorreremos sobre alfabetização e letramento, na perspectiva de diferentes autores, bem como sobre os princípios e ações do Pacto Nacional pela Alfabetização na Idade Certa (PNAIC). No segundo momento, trataremos da análise e discussão dos dados coletados por meio da entrevista com a professora, da análise do PPP, dos materiais didáticos e do grupo focal com os alunos, perpassando pela concepção da professora sobre a alfabetização e letramento, pelas práticas de leitura e de escrita utilizadas em sala de aula e pelos sentidos que os alunos atribuem às atividades de leitura e escrita. E por fím, as considerações finais apontam os principais resultados da pesquisa, tendo em vista o objeto de estudo.

\section{ALFABETIZAÇÃO NA PERS- PECTIVA DO LETRAMENTO}

Neste tópico, apresentamos reflexões sobre alfabetização e letramento, por meio de autores renomados, níveis de escrita, práticas de leitura e escrita e por fim, destacamos as ações e princípios do PNAIC.

A alfabetização no Brasil ganhou um novo sentido a partir das pesquisas sobre a Psicogênese da Língua Escrita. (Ferreiro e Teberosky, 1991) que destacaram necessidades de novos e diferentes métodos de alfabe- tização de forma contextualizada e que tivesse significado para o educando que está inserido no ciclo de alfabetização, de forma que o educando fosse visto como uma pessoa que traz em si o conhecimento e passa por processos de aprendizagens e não mais num modelo de ensino em que o educando memorizava, escrevia e não sabia a função do que escrevia e nem refletia sobre o que estava aprendendo.

De acordo com a teoria exposta pelas autoras em Psicogênese da Língua Escrita, todas as crianças passam por cinco níveis estruturais da linguagem escrita até que estejam alfabetizadas. Para Ferreiro e Teberosky (1991 p.183-213) a evolução da aprendizagem da criança se dá nas fases abaixo:

- Nível 1: Neste nível, escrever é reproduzir os traços típicos da escrita que a criança identifica como a forma básica de escrita. Se esta forma básica é a escrita de imprensa, teremos grafismo separados entre si, compostos de linha curvas e religadas entre si com uma linha ondulada como forma de base, na qual se inseram[sic] curvas fechadas ou semifechadas.

- Nível 2: A hipótese central deste nível é a seguinte: para poder ler coisas diferentes (isto é, atribuir significados diferentes) deve haver uma diferença objetiva nas escritas. O progresso gráfico mais evidente é que a forma dos grafismos é mais definida, mais próxima à das letras.

- Nível 3: Este nível está caracterizado pela tentativa de dar um valor sonoro a cada uma das letras que compõem uma escrita. Nesta tentativa, a criança passa por um período de maior importância evolutiva: cada letra vale por uma sílaba. É o surgimento do que chamaremos a hipótese silábica.

- Nível 4: Passagem da hipótese silábica para a alfabética. A criança abandona a hipótese silábica e descobre a necessidade de fazer uma análise que vá "mais além" da sílaba pelo conflito entre a hipótese silábica e a exigência de quantidade mínima de grafias.

- Nível 5: A escrita alfabética constitui o final desta evolução. Ao chegar a este nível, a criança já frequentou a "barreira do código"; compreendeu que cada um dos caracteres da escrita corresponde a valores sonoros menores que a sílaba, e realiza sistematicamente uma análise sonora dos fonemas das palavras que vai escrever.

Dessa forma, o aprendizado do educando no que se refere à leitura e à escrita se dá num processo contínuo, de superação em cada nível e assim acontece a construção do saber da criança. Esse aprendizado é constante, pois por meio da assimilação dos conteúdos a criança desenvolve a cada nível um conhecimento dando significado aos saberes já construídos. Segundo Barbosa (1994 p.73)

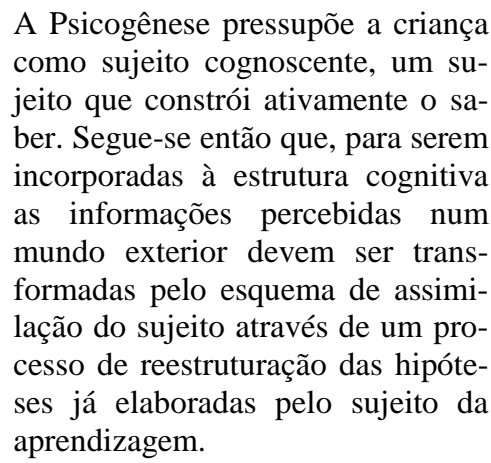

A Psicogênese pressupõe a criança como sujeito cognoscente, um suber. Segue-se então que, para serem incorporadas à estrutura cognitiva as informações percebidas num mundo exterior devem ser transformadas pelo esquema de assimilação do sujeito através de um processo de reestruturação das hipóteaprendizagem. 
$\mathrm{O}$ autor vem explicar como a criança constrói o seu saber a partir das interações com o meio em que vive, apropriando-se de informações que depois de passar por uma transformação, lhes darão suporte para construção ativa do saber, já que as crianças elaboram hipóteses sobre a escrita, pois têm conhecimentos prévios estruturados. Nesse prisma, é que hoje se defende uma alfabetização numa perspectiva de letramento. Para Santiago (2015, p. 94)

É preciso respeitar a etapa de vida, de desenvolvimento de cada criança, valorizando o conhecimento prévio ao ambiente escolar, a fim de que possam mediar conhecimentos e saberes, potencializando as capacidades na promoção do aprendizado. Cada criança aprende de uma maneira única e é papel da escola propiciar a possibilidade de aprendizado para todos.

Sendo assim, podemos observar na escrita da autora que o professor deve valorizar o saber dos educandos, o tempo e a maneira de aprender de cada um para melhor desenvolver a aprendizagem.

\subsection{Mas afinal o que é Alfabetização e Letramento?}

De acordo com Soares (1985, p. 20) "o termo alfabetização não ultrapassa o significado de "levar a aquisição do alfabeto", ou seja, ensinar o código da língua escrita, ensinar as habilidades de ler e escrever". Mas para que haja encantamento pela leitura e escrita, o professor deve fazer uma mediação prazerosa de forma que os educandos aprendam e compreendam com intensidade, pois se for concebida como tarefa a ser cumprida o educando perde o encanto.

Nessa perspectiva, o professor precisa oportunizar aos educandos momentos de contato com a escrita e com a diversidade da leitura, mas para que isso ocorra é imprescindível o significado que o docente atribui para a escrita e a leitura.

Já o letramento é descrito pela autora como "estado ou a condição de quem não apenas sabe ler ou escrever, mas cultiva e exerce as práticas sociais que usam a escrita" (SOARES, 1999 p. 47). Assim, é fundamental que o educando saiba utilizar a leitura e a escrita na sociedade em que está inserido participando ativamente com suas opiniões e não por aquilo que lhe é imposto.

\section{É preciso alfabetizar numa} perspectiva de letramento, conforme afirma Soares (2007 p. 3):

A criança deve entrar no mundo da escrita usando dois 'passaportes': precisa apropriar-se da tecnologia da escrita, pela alfabetização, e precisa identificar os diferentes usos e funções da escrita vivenciando diferentes práticas de leitura e de escrita, pelo processo de letramento. Se lhe é oferecido um dos 'passaportes' - se apenas se alfabetiza sem conviver com práticas reais de leitura e de escrita - formará um conceito distorcido e parcial do mundo da escrita; se usa apenas o outro 'passaporte' - se apenas, ou sobretudo, é levada ao letramento, sem a apropriação adequada da tecnologia da escrita - saberá para que serve a língua escrita, mas não saberá se servir dela. Assim, para a inserção plena da criança no mundo da escrita, é fundamental que alfabetização e letramento sejam processos simultâneos e indissociáveis.

Essa junção de alfabetização e letramento auxilia os educandos no desenvolvimento da aprendizagem, pois por meio deste processo formará leitores/escritores críticos para construção da sociedade. E assim o professor deve pautar a própria prática pedagógica de maneira que faça a mediação dos dois processos. Para Geraldi (2010 p. 2) os processos alfabetização e letramento são definidos desta forma:

\begin{abstract}
[...] em que a alfabetização teria por finalidade ensinar as convenções do código escrito e o letramento teria por finalidade proporcionar a inserção dessas mesmas crianças no mundo da cultura escrita, ambas as finalidades explicadas considerando as exigências sociais de uso da escrita e da leitura na sociedade, sem qualquer questionamento a respeito destas exigências, chamadas de demandas sociais de leitura e escrita.
\end{abstract}

O hábito de leitura deve começar antes do educando saber ler convencionalmente, pois é imprescindível que a leitura seja uma rotina para que o educando possa tomar gosto e encontrar significados na diversidade das leituras. Afirmamos com base nos Parâmetros Curriculares Nacionais para o Ensino Fundamental (PCNEF): "A leitura é uma prática social que envolve atitudes, gestos e habilidades que são mobilizados pelo leitor, tanto no ato de leitura propriamente dito, como no que antecede a leitura e no que decorre dela". (BRASIL, 2008 p.40).

A leitura faz parte do cotidiano do educando, pois existe leitura em tudo que permeia sua vida, revistas, jornais, revistas em quadrinhos, propagandas de televisão, rótulos de alimentos, bulas de remédios, entre outros. Ouvimos constantemente que ler é primordial para o desenvolvimento da criança, que amplia o vocabulário, desperta o imaginário, desenvolve a criatividade e ainda conhece os diversos textos existentes e suas finalidades na sua vivência. Nesse sentido, coadunando com Solé (2014), entendemos que a leitura acontece num processo de interação entre o leitor e o texto.

Para as crianças que estão no processo de aprendizagem isso é um pouco mais complexo, pois é necessá- 
rio a intervenção de um adulto no caso da escola do professor para mediar o desenvolvimento do aprendizado de forma que o educando consiga fazer uma leitura com mais fluência.

Conforme Caligari (1993, p. 155) existem três tipos de leituras que são: "A leitura ouvida, vista e falada". $\mathrm{Na}$ ouvida, as crianças têm seu primeiro contato com a leitura, pois os adultos leem para elas histórias; na vista as crianças têm o contato visual com estas histórias e na falada, as crianças reproduzem o que ouviram e viram. A criança desde pequena formula ideia daquilo que vê, quando ela tem contato com livro, as imagens vão produzindo nela imaginação e se o adulto perguntar, o que você está fazendo? Estou lendo, responde ela e no seu imaginário ela conta histórias ao adulto referente ao que ver, por isso é muito importante esse contato das crianças com a diversidade das leituras.

A escrita precisa fazer parte do aprendizado da criança já que essa é uma outra forma de comunicação necessária na sociedade em que estamos inseridos e é tão importante quanto o ato de ler, e por meio da escrita a criança expressa o que vive. Segundo Rizzo (1990, p. 103) "O ato de escrever exige o domínio de uma série de movimentos coordenados e uma atividade intelectual mais complexa que a da leitura". Então, qualquer situação vivenciada ou imaginária da criança será representada por meio da escrita, é uma outra linguagem que vai sempre refletir a oralidade e não pode estar dissociados. Partindo dessa ideia, escrever para a criança é um processo natural. Silva (1994, p.17-18) destaca:

Não é preciso ser pesquisador para notar que a escrita é uma atividade que atrai a atenção da criança desde muito cedo. Esse precoce interesse pelo lápis e papel faz com que, aos dois ou três anos de idade, ela queira manuseá-los, especialmente, se vir alguém, por perto, fazendo o mesmo. Se lhe for dado material, sem dúvida alguma, ela rabiscará descontinuamente e, se questionada, dirá que está escrevendo.

A escrita é um ato que faz parte da vida da criança desde cedo e principalmente se convive com adultos que demonstram diariamente essa atitude para elas, inicialmente a criança fará por imitação ao adulto e desse modo adentra ao mundo da escrita, e na escola ela vai receber as intervenções precisas de elaboração dessa escrita. Para Weisz (2009) se o educando escreve "muleci", representando moleque não podemos dizer que está errado, pois ele aprendeu a escrever segundo suas hipóteses como se escreve casa e cavalo com c pensa que moleque pode se escrever do mesmo jeito, considerando isso o educando só não sabe as regras gramaticais.

As práticas de leitura e escrita são para auxiliar no processo de desenvolvimento do educando, pois quanto mais contato com essas práticas tiver o educando mais ajudará na sua aprendizagem. Para Cagliari (1993 p.148)

A atividade fundamental desenvolvida pela a escola para a formação dos alunos é a leitura. É muito mais importante saber ler do que saber escrever. $\mathrm{O}$ melhor que a escola pode oferecer para os alunos deve estar voltado para a leitura. [...] A leitura é a extensão da escola na vida das pessoas. A maioria do que se deve aprender na vida terá de ser conseguido através da leitura fora da escola. A leitura é uma herança maior do que qualquer diploma.

Portanto, a leitura é imprescindível para a formação de bons leitores e esta prática não deve ficar limitada apenas à sala de aula, deve permear toda a vida do educando, para isso o mesmo precisa conviver em um con- texto que lhe proporcione os diversos tipos de leitura ${ }^{3}$.

A leitura e escrita precisam de um diálogo constante, pensando assim os dois processos não podem estar dissociados e a escola tem que focar em estratégias pedagógicas para trabalhar simultaneamente as duas práticas.

Na opinião de Ferreiro (2011, p. 14) "A escrita pode ser considerada como uma representação da linguagem ou como um código da transcrição gráfica das unidades sonoras". De forma que os educandos desenvolvam seus raciocínios diante do processo da escrita, pois aquilo que inicialmente é errado para o adulto, para a criança tem significado e sentido em sua escrita, ela representa o que deseja escrever, mesmo que para o adulto não haja conexão com o real, e a medida de seu desenvolvimento a escrita vai tomando forma, a criança começa a perceber que falta algo para complementar a palavra, dar sentido ao que se escreve até conhecer as letras e as unidades sonoras e essas darem significados uma as outras.

Para Rizzo (1990, p.153) a linguagem escrita tem suas características:

$1^{\circ}$ A linguagem escrita existe porque existe uma linguagem oral, que é a necessidade social de comunicação entre os indivíduos;

$2^{\circ}$ A linguagem escrita reflete, portanto, a linguagem oral, mas tem como função primordial registrar, por tempo indeterminado, alguma comunicação, visto que a linguagem articulada (sem ser gravada) desaparece no tempo e no espaço, logo a seguir de sua emissão oral.

Por meio do conhecimento dessas características de linguagem apontadas pela autora o alfabetizador disponibilizará atividades ao educando que facilitarão seu aprendizado na

${ }^{3}$ Livros, revistas, jornais, histórias de quadrinhos, histórias muda, etc. 
escrita, pois existem crianças que só tem o contato com essas práticas de leitura e escrita no ambiente escolar.

\subsection{PNAIC - Pacto Nacional pela Alfabetização na idade certa}

O Pacto Nacional pela Alfabetização na Idade Certa (PNAIC) foi elaborado com a intenção de alfabetizar as crianças até os oito anos de idade, sua proposta é de formar professores alfabetizadores para atuarem no ciclo de alfabetização. Essa formação é desenvolvida por meio de cadernos distribuídos pelo Ministério da Educação (MEC) e cada ano busca-se aprimorar a proposta de acordo com as demandas escolares. Para Machado (2016, p. 80) "Compreender a realidade dos alunos e as condições em que se dá a sua educação pode possibilitar a criação de políticas públicas melhor dimensionadas". A proposta do PNAIC vem se delineando desde 2008, mas só em 2012 foi implementada. Brasil (2015, p.23) "Sobre a base legal, além da Portaria ${ }^{\circ}$ 867, 4 de julho de 2012, que institui o Pacto Nacional pela Alfabetização na Idade Certa, bem como as ações e diretrizes gerais do programa".

As ações do PNAIC são apoiadas em quatro eixos: formação continuada presencial para professores alfabetizadores e seus orientadores de estudo; materiais didáticos, obras literárias, obras de apoio pedagógico, jogos e tecnologias educacionais; avaliações sistemáticas; gestão, controle social e mobilização. "O PNAIC constitui um conjunto integrado de ações, materiais e referências curriculares e pedagógicas". (BRASIL, 2015, p. 18). Esse programa disponibilizado pelo MEC tem como eixo principal a formação continuada dos docentes alfabetizadores. Diante do exposto todos esses elementos são essenciais para efetivação da alfabetização na idade certa.

\section{AS PRÁTICAS DE LEITURAS E ESCRITAS EM UMA TURMA DO TERCEIRO ANO DO CICLO DE ALFABETIZAÇÃO DE UMA ES- COLA DE GUANAMBI}

No primeiro momento vamos analisar os dados coletados por meio da entrevista com a professora, tomando por base as seguintes unidades de análises: A concepção da professora sobre a alfabetização e o letramento; As práticas de leitura e de escrita utilizadas em sala de aula e como essas práticas influenciam no processo de aprendizagem dos alunos.

No segundo momento, a análise do PPP e das obras complementares do PNAIC e observação dos materiais didáticos utilizados durante as aulas.

E por último, analisar os dados coletados através do grupo focal para conhecer os sentidos que os alunos atribuem às atividades de leitura e escrita trabalhadas em sala de aula, seu olhar diante das práticas de leitura e escrita mediadas pela professora.

\subsection{O Olhar da Professora: as con-} cepções de alfabetização e letramento e práticas de leitura e escrita

Para discorrer sobre este tópico, iremos retomar às questões de estudo já mencionadas na introdução. Como a professora concebe a alfabetização e o letramento? Quais as práticas de leitura e escrita são mobilizadas pela professora em sala de aula?

Ao entrevistar a professora sobre sua concepção de alfabetização e letramento, percebemos que a interlocutora concebe a alfabetização como um processo importante para a cons- trução do conhecimento do educando, destacando que letramento é quando o educando entende o que leu e escreveu. "Olha, são denominações que a gente fica muito confusa, mas, Letramento para mim é quando o aluno ler, escreve e entende o que ele leu e escreveu e tem como se comunicar através dessa leitura e dessa escrita". (PROFESSORA, Escola Esperança do Amanhã, novembro de 2017).

Partindo dessa premissa, a interlocutora dialoga com os teóricos que estudam a questão em discussão. Segundo Soares (1999, p.18) letramento é: "O estado ou a condição que adquire um grupo social ou um indivíduo como consequência de ter-se apropriado da escrita". Logo o educando que se apropria da escrita está atendendo as perspectivas do letramento.

A reflexão da professora nos remete ao PNAIC quando discorre a concepção da alfabetização na perspectiva de letramento (BRASIL 2015, p.21):

\footnotetext{
Ou seja, entende-se e defende-se que é preciso que a criança domine o Sistema de Escrita Alfabética, mas que também desenvolva habilidades de fazer uso desse sistema em diversas situações comunicativas, com autonomia.
}

Continuamos a entrevista para saber quais as práticas de leitura e escrita eram trabalhadas pela professora para contribuir no ensino/aprendizagem da turma e interrogamos: Quais práticas de leituras e escritas são realizadas em sala de aula? Que materiais são utilizados para esse trabalho da escrita e leitura? E tivemos a resposta a seguir:

Olha, eu sempre trabalho com eles com histórias[...] tem os livros do PNAIC que nós recebemos, tem os livros da biblioteca, tem o próprio livro didático que tem textos vas- 
tos[...]de vários segmentos assim, fábulas, histórias[...] tem o Projeto Itaú que eu trago para sala de aula né que na época das crianças ganha-se os livros, eu leio e acabo doando para os próprios alunos (PROFESSORA, Escola Esperança do Amanhã, novembro de 2017).

Diante da narrativa, percebemos que as práticas de leitura e escrita e os materiais utilizados pela professora são diversificados. A interlocutora utiliza uma variedade de livros, tanto os didáticos, como as obras complementares do acervo do PNAIC, livros da biblioteca e entre outros nas suas práticas. Demonstrando a necessidade de se ter acesso a diversidade de leitura que irá formar bons leitores/escritores.

Sua narrativa corrobora com nossa observação em relação aos materiais didáticos por ela utilizado em sala de aula, que foram os livros didáticos do $3^{\circ}$ ano e também os do PNAIC de Língua Portuguesa e Matemática, como as obras complementares do acervo do PNAIC, cadernos, tangram.

Partindo da proposta do PNAIC - Pacto Nacional pela Alfabetização na Idade Certa que tem um compromisso firmado pelos governos federal, do Distrito Federal, dos Estados e Municípios de garantir que as crianças estejam alfabetizadas até os oito anos de idade, ao final do $3^{\circ}$ ano do ensino fundamental conforme a Portaria $n^{\circ}$ 867, de 4 de julho de 2012, levantamos alguns questionamentos para a professora a respeito desse processo: Perguntamos: Gostaríamos de saber o que pensa sobre o processo de alfabetização? E obtivemos a seguinte resposta:

Olha, eu penso que é um processo muito importante para a formação dos nossos alunos [...] o $3^{\circ}$ ano é a efetivação desse processo, então eu penso que é muito importante, e é muito complicado também porque a maioria dos alunos já vêm de si- tuações fora daqui da escola que acaba impedindo esse processo. É um processo também muito demorado, é um processo que depende não somente do educador, mas também é dos alunos e eu falo até consequência da família também. (PROFESSORA, Escola Esperança do Amanhã, novembro de 2017).

Por meio da resposta da professora, podemos observar que o apoio da família é fundamental na formação dos educandos, mas que os diversos fatores externos à escola também dificultam o aprendizado do educando. Em nossa observação, contemplamos a preocupação da professora não só com a aprendizagem de seus educandos em relação com a leitura e a escrita, essa também se envolvia com a questões sociais vividas por eles.

Por isso ressaltamos que a professora não é displicente ao contexto social em que vivem os seus educandos, pois demonstra constantes preocupações com a formação deles. Isso nos remete que que o processo ensino aprendizagem perpassa por condicionantes políticos, estruturais, sociais e econômicos. Ademais, é importante investimento na formação continuada dos educadores para uma prática crítica e transformadora. Para Assencio (2016, p. 128).

A prática pedagógica do professor
perpassa pelas experiências viven-
ciadas em sala de aula, articuladas
com a participação em formações
continuadas. A prática do professor
não é inata, pois ser professor é ser
um pesquisador diário de sua ação,
é estar aberto a conhecer novas
ideias, é aprender no dia a dia da
sala de aula e compartilhar momen-
tos, tendo a consciência da necessi-
dade da formação continuada den-
tro e fora da escola.

Dando continuidade, indagamos sobre o desenvolvimento dos educandos no que se refere à leitura $\mathrm{e}$ escrita e mais uma vez a professora relatou problemas externos à escola que impede o avanço dos educandos. A pergunta foi: Como você vê o desenvolvimento dos alunos na aquisição da leitura e escrita?

Olha, levando em consideração a minha turma, esse desenvolvimento[...] ele tem sido bem lento, porque são alunos, é[...] que trazem problemas familiares pra dentro da sala de aula, a gente tenta contornar dentro das nossas possibilidades assim, mas eu vi que houve uma evolução do início do ano até agora, que me satisfez muito. (PROFESSORA, Escola Esperança do Amanhã, novembro de 2017).

Diante do exposto, é percebível que o contexto familiar e social em que esses educandos estão inseridos pouco favorece para a construção do conhecimento, o que certamente dificulta o trabalho desenvolvido pela professora.

Para melhor compreensão deste contexto solicitamos que a professora falasse sobre o PNAIC já que este expõe, a necessidade de o educando está alfabetizado aos oito anos: Nós gostaríamos que você falasse um pouquinho sobre o PNAIC. E a narrativa foi essa:

Então é um projeto do governo né que, é uma formação na realidade para professores e eu faço parte já é o terceiro ano, eu acredito que é um auxílio né que faz com que a gente tenha mais segurança ao tratar com os alunos dentro da sala de aula, os monitores, as coordenadoras dão um apoio total para a gente e sempre voltado para a aquisição da leitura e a aquisição da escrita para a evolução dos alunos (PROFESSORA, Escola Esperança do Amanhã, novembro de 2017).

Já no que diz respeito ao PNAIC a professora informou que os profissionais que atuam no ciclo de alfabetização precisam fazer a formação para lecionar, e no caso específico 
da interlocutora em questão, que trabalha com o $3^{\circ}$ ano, recebe a formação semanalmente no Centro de Treinamento Pedagógico-CETEP. Essas afirmações nos levam a reflexão do que está descrito no caderno de apresentação do PNAIC que para atuarem como formadores do ciclo de alfabetização é imprescindível que recebam a formação.

Logo, percebemos que a interlocutora demonstra a importância do PNAIC e em nossas observações diárias percebemos que ela conhece a proposta do PNAIC. Fundamentado no PNAIC prosseguimos com mais outro questionamento a professora: Como é essa formação com os professores que vão trabalhar diretamente com o PNAIC? Ela declarou:

[...] se você tiver com uma turma do $1^{\circ}$ ao $3^{\circ}$ Ano você é obrigatório participar dessa formação do PNAIC que é feita no CETEP, essa formação acontece durante todo o ano, é as quartas feiras o que eu faço parte é as quartas feiras começa às 7:30h e termina às $11: 30$ h são 4 horas de formação onde nós colocamos o processo da sala de aula e eles dão o apoio para a gente, os coordenadores nos apoiam (PROFESSORA, Escola Esperança do Amanhã, novembro de 2017).

Os dados demonstram que os professores recebem suporte pedagógico para a respectiva atuação no pacto, conforme descrito no documento do PNAIC.

Em 2013, a ênfase do PNAIC baseou-se na formação em Língua Portuguesa e, em 2104, na formação em Matemática. Em 2015, a novidade é a ampliação para as demais áreas do conhecimento, de forma integrada, abrangendo a educação integral das crianças nesse início do processo de escolarização. Para esta nova etapa da formação, cada orientados de estudos e professor alfabetizador receberá um kit de formação contendo um caderno de apresentação, um caderno para gestores e equipe pedagógica e dez cadernos com textos teóricos sobre os temas da formação, relatos de professores e sugestões de atividades (BRASIL, 2015, p. 7).

Contudo, durante a observação em sala de aula e os diálogos com a professora, percebemos que os módulos de Matemática e Língua Portuguesa para o $3^{\circ}$ ano não tinham chegado até o momento da pesquisa. A professora estava utilizando o módulo do $2^{\circ}$ Ano de 2016 com a turma.

Em relação ao programa PNAIC, evidenciamos que a temática e indagações sobre o ensino/aprendizagem partiram de debates com profissionais da educação para chegar no processo atual, mas observamos que no espaço de nossa pesquisa esses debates e indagações estão longe de chegar ao fim. Isso foi comprovado durante o período em que estávamos observando e coletando dados para a nossa produção, que muitos educandos chegam ao final do ciclo de alfabetização sem estarem alfabetizados e ainda tem a questão da distorção de idade/série.

Diante disso, pedimos que à professora falasse sobre suas inquietações e angústias com relação aos educandos que chegam no final do ciclo de alfabetização e ainda não estão alfabetizados. A docente desabafou:

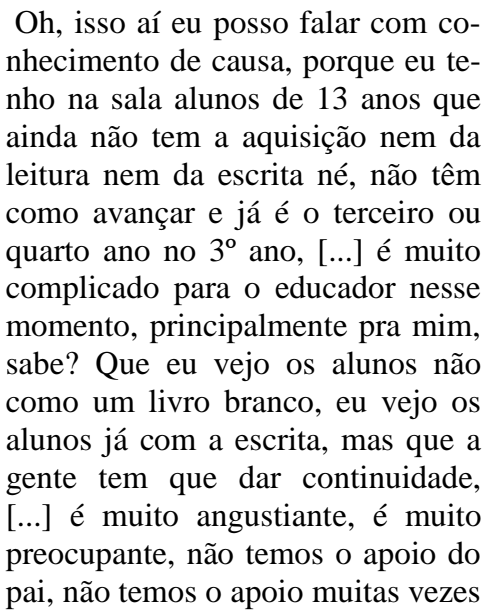

até da própria escola, porque também são várias turmas e[...] isso me deixa muito inquieta. Alguns alunos até eu fiz um projeto fora da escola, levei pra minha casa, tentei ajudar, só que vai um dia, depois não vai [...] tem também a questão de aluno que chega no meio do ano, [...], que vem de outras escolas, ou de outras cidades, que não têm também essa evolução, têm os alunos que saem daqui para outra escola, então é muito complicado, são ns fatores que não ajudam e traz mais inquietação ainda. (PROFESSORA, Escola Esperança do Amanhã, novembro de 2017).

É pertinente ressaltar, que observamos ao longo dos dias a angústia da professora por conta dessa situação descrita acima, que ela tentou levar os educandos para a sua casa para ajudálos, porém não obteve sucesso. Por diversas vezes conversou conosco a respeito desse problema e expressava preocupação.

Diante de suas angústias quanto aos educandos que não avançam no processo de da leitura e escrita, e da falta de acompanhamento da família, indagamos para ela: Na sua visão se houvesse um acompanhamento da família iria ajudar nesse processo. A professora foi firme ao responder: “sim” (PROFESSORA, Escola Esperança do Amanhã, novembro de 2017).

Essas reflexões apontam que um dos possíveis fatores que pode dificultar que os educandos cheguem no final do ciclo de alfabetização sem estarem alfabetizados, certamente é a falta de apoio de alguns responsáveis, talvez por não serem alfabetizados e por isso não podem ajudar os filhos nas atividades, ou ainda pelo contexto social em que esses educandos estão inseridos. Entendemos, que a parceria escola e família, mesmo diante do contexto social vivido pelos educandos poderia colaborar com o processo de ensino/aprendizagem dos educandos. Weisz (2009, p 48-49) descreve: 
As crianças vindas de um mundo cultural semelhante ao que é valorizado na escola, já chegam a escola com enormes vantagens em relação às demais. Para elas a escola será muito mais fácil, porque está em consonância com a cultura da família e do seu ambiente. Não se pode dizer o mesmo das crianças que vêm de comunidades onde as pessoas têm menor grau de escolaridade e estão, portanto, mais distantes dos usos cotidianos dos conteúdos que a escola propõe. Elas não dispõem do tipo de conhecimento com o qual a escola habitualmente conta e dependem exclusivamente da escola para aprender os conteúdos escolares, pois não têm, em casa a quem recorrer.

Em relação ao Projeto Político Pedagógico (PPP) ${ }^{4}$ da escola podemos observar que as questões sobre a alfabetização são contempladas nas metas:

- Alfabetizar $80 \%$ das crianças até aos nove anos de idade, acompanhando os resultados através do diagnóstico e avaliações;

- Proporcionar o desenvolvimento da aprendizagem do aluno adequando ao ano de estudo, através de aulas de reforço, atividades diferenciadas e extraescolares, para diminuir em $80 \%$ a distorção idade/série.

Nese sentido, conforme a proposta da escola, as crianças devem ser alfabetizadas até os nove anos de idade e não com oito anos, como consta na base das diretrizes do Pacto Nacional pela Alfabetização na Idade Certa (PNAIC). Vemos que na prática ainda não se concretizaram essas metas.

Nos planos de ações sobre leitura e escrita constam no PPP5:

${ }^{4}$ Fonte: PPP da Escola 2015/2016.

${ }^{5}$ Fonte: PPP da Escola 2015/2016. a) Proporcionar melhoria significativa de leitura, interpretação e escrita, por acreditar ser a condição primordial para seu desenvolvimento;

b) Envolvimento de todos os professores, em todas as áreas do conhecimento, na valorização da leitura e escrita em todas as aulas;

c) Desenvolvimento de "Projeto de Leitura" envolvendo todos os alunos e professores;

d) Incentivação à prática do brincar em grupo, para desenvolver estratégias importantes, como seguir regras, respeitar limites, respeitar o outro, cuidar do que é nosso;

e) Divulgação para a comunidade sobre o empenho da escola em desenvolver o gosto pela leitura em todos os alunos, conscientizando a todos da sua importância para o crescimento do educando;

f) Incentivar a participação dos alunos nas oficinas do Programa Mais Educação, proporcionando a prática de esporte, cultura e desenvolvimento de estratégias.

Para Schuvester (2009, p.10) “O projeto político pedagógico (PPP) revela a identidade de cada escola, por ser um instrumento que expressa as intenções do que se pretende realizar...”. O PPP da escola precisa ser pensado a partir das necessidades da instituição, em parceria com a comunidade escolar e organizado de maneira que atenda todas as demandas da escola, pois segundo a LDB 93.94 de 1996, a instituição tem autonomia para criação do PPP mediante diálogo, debate e reflexão.

Portanto, é Fundamental que a parceria escola e comunidade aconteça para que os resultados pretendidos nas ações e metas posta pelo PPP da escola pesquisada tenha êxito. Com relação ao PPP e o trabalho desenvolvido pela professora, vimos que ela foca suas atividades em leitura e escrita para que o maior número de educando seja alfabetizado conforme estabelece o documento em suas metas e ações.

\subsection{Os materiais didáticos utilizados em sala de aula}

Os materiais didáticos que a professora utilizou durante a nossa observação foram os seguintes: os livros didáticos do MEC adotado pela escola, os módulos de Português e Matemática do $2^{\circ}$ Ano e os livros complementares do acervo do PNAIC que auxiliam a mediação da professora no ensino/aprendizagem dos educandos. Vale ressaltar que esses materiais utilizados eram com foco na leitura e na escrita

Existem vários materiais que também podem ser considerados materiais didáticos tais como: revistas, músicas, apostilas, tirinhas, xerox, etc e cabe ao professor selecioná-los de forma criteriosa para que possam ajudar na mediação e no aprofundamento do conhecimento do educando sem ficar restrito ao livro didático oferecido pelo MEC e adotado pela escola. $\mathrm{O}$ livro deve ser um suporte do professor, mas não o único material a ser utilizado na sala, daí a importância de escolher bem o material didático para trabalhar em sala.

Para Soares (2002) o livro didático ampliou sua função. Além de propiciar conhecimentos à linguagem escrita, possibilita a construção das potencialidades intelectuais e contribui para a formação social e política das pessoas. Nesse sentido, o livro didático é para o educando um meio de apren- 
dizado que o prepara para viver na sociedade.

A professora utilizava bem esta ferramenta, incentivando aos alunos lerem e falarem sobre o que estavam entendo, como também a zelarem este material didático.

Em relação ao acervo do PNAIC, a professora trabalhava os livros com os educandos de forma diversificada, uns dias eram leitura para deleite, outros fazia questionamentos sobre os livros de modo geral. São livros com histórias ilustradas e outros com histórias mudas que falam de diversas temáticas sobre a vida cotidiana.

\begin{abstract}
As obras complementares são recursos que podem favorecer a ampliação do letramento da criança e da reflexão sobre o sistema de escrita alfabética, além disso, pela característica dos livros que compõem os acervos, é possível ainda favorecer o contato das crianças com variadas áreas do conhecimento escolar, possibilitando descobertas por meio de situações prazerosas de leitura. (BRASIL, 2012b p.21).
\end{abstract}

Para elucidar a pesquisa fizemos uma análise apenas das obras complementares do acervo do PNAIC. Para análise de obra literária é imprescindível seguir alguns critérios. Segundo Andrade (2007, p.88): “O primeiro passo para se pensar a qualidade do livro infantil é analisar forma e conteúdo simultaneamente, ou seja, a relação entre o projeto como um todo, incluindo ilustração, tamanho de letra, cores, diagramação, etc. e o texto".

No contexto dos livros percebemos que o projeto gráfico contém características importantes como a visibilidade por meio da ilustração, no seus formatos, tipos e tamanhos de letras, capas e contracapas, existem funcionalidades entre os sumários, glossários e dados bibliográficos, dos autores e ilustradores. A qualidade e a textura do papel são boas, elas retratam as imagens com luminosidade, as técnicas das cores empregadas nas imagens foram adequadas e têm uma dosagem de informações suficientes entre os textos para compreensão dos educandos. No que se refere a pertinência da temática, observamos que os temas estão relacionados com o cotidiano dos educandos e assim encontram sentidos na leitura dos livros.

Os Acervos Complementares distribuídos pelo MEC têm características próprias. Assim como os livros didáticos, as obras que os compõem estão em sintonia com os currículos, na medida em que não só abordam temas de interesse escolar, como foram concebidos e realizados de forma a favorecer a aprendizagem. Por outro lado, são 'livros de leitura' como tantos outros, caracterizando-se por ampla circulação social. Portanto preenchem funções diversificadas, no processo de formação do aprendiz, ao mesmo tempo em que seduzem e entretêm o leitor (BRASIL, 2012c, p. 23).

Posto isso, as temáticas dos livros didáticos contemplam a diversidade sócio cultural que faz relação com assuntos trabalhados em sala de aula. Vimos que a professora disponibilizava as obras para os educandos escolherem o que queriam ler e a partir disso ela os questionavam individualmente a respeito do livro lido, tipo: "Sobre o que fala o livro? O que você entendeu da história?" Entre outras. (DIÁRIO DE CAMPO, novembro de 2017). Ademais a professora oferecia aos educandos atividades de construção de textos individuais. E para aqueles que ainda não dominavam a leitura e a escrita era pedido que desenhassem o que entenderam da história.

\subsection{O olhar dos alunos sobre as prá- ticas de leitura e escrita}

Para identificarmos a percepção dos alunos sobre as atividades de ensino/aprendizagem relacionadas à leitura e à escrita, aplicamos a técnica do grupo focal, o qual foi realizado em duas seções. A primeira com todos os alunos participantes e teve duração de 45 minutos, já a segunda seção fizemos com vários grupinhos (4 e 5 educandos) e teve duração de 2 horas e 45 minutos, de acordo com o tempo os educandos iam fazendo comentários. Para a execução da técnica umas das pesquisadoras fez a moderação e a outra foi a assistente responsável pelo registro da conversação. Para Gatti (2005, p. 11)

O trabalho com grupos focais per-
mite compreender processos de
construção da realidade por deter-
minados grupos sociais, compreen-
der práticas cotidianas, ações e rea-
ções a fatos e eventos, comporta-
mentos e atitudes, constituindo-se
uma técnica importante para o co-
nhecimento das representações,
percepções, crenças, hábitos, valo-
res, restrições, preconceitos, lin-
guagens e simbologias prevalentes
no trato de uma dada questão por
pessoas que partilham traços em
comum, relevantes para o estudo do
problema.

A técnica de grupo focal foi modificada, para ser adaptada conforme ao contexto escolar e solicitação da professora da turma de fazermos com todos educandos. Inicialmente arrumamos as cadeiras em círculo e convidamos os educandos presentes para uma roda de conversa e nos apresentamos, relembramos os nossos objetivos com o trabalho de campo. A professora ficou na primeira seção e também falou da importância dos educandos contribuírem com a nossa pesquisa, motivando-os falarem, pois no primeiro momento eles estavam tímidos. 
Iniciando o diálogo, informarmos sobre a idade dos/as educandos/as. E as respostas foram: " 8 anos, 9 anos, 10 anos, 11 anos, 13 anos" (Grupo focal com educandos/as da Escola Esperança do Amanhã, novembro de 2017). Vale ressaltar que a maioria estão em defasagem de idade/série.

Para Arroyo (2015, p. 29):

A taxa de pessoas com 16 anos completos e com ensino fundamental concluído é de apenas $43 \%$ entre os mais pobres, enquanto entre os mais ricos é de $86 \%$, confirmando a grande incidência de distorção idade-série entre os adolescentes mais pobres.

Desta forma, a abordagem do autor reforça que a defasagem nos estudos dos educandos se dá num contexto de sua realidade em periferia e de classe baixa. Continuamos com as indagações: Com quem vocês moram? Obtivemos as narrativas: "Moro com a minha mãe, moro os meus pais, moro com a minha avó, moro com os meus irmãos" (Grupo focal com educandos/as da Escola Esperança do Amanhã, novembro de 2017). Essas respostas nos levam a refletir sobre a quantidade de crianças que atualmente moram apenas com a mãe. Esses dados vêm corroborar com a pesquisa realizada pelo Instituto Brasileiro de Geografia e Estatística (IBGE), sobre a composição das famílias brasileiras. Segundo este órgão, de 2000 a 2010, tem crescido o número de mulheres que assumem os seus filhos sozinhas (IBGE, 2012).

Prosseguimos perguntando aos educandos a quantidade de irmãos. "1 irmão, 2 irmãos, 3 irmãos, 4 irmãos, 5 irmãos, 7 irmãos" (Grupo focal com educandos/as da Escola Esperança do Amanhã, novembro de 2017). Porém, nem todos os irmãos moram na mesma casa, há irmãos que uns vivem com o pai e outros com a mãe e também alguns com avó.

Perguntamos também: Os irmãos estudam na escola? E eles declararam:

Tenho 4 irmãos que estudam na escola (3 no $3^{\circ}$ Ano e 1 na Educação Infantil), tenho 1 irmão que estuda no $6^{\circ}$ ano, tenho 4 irmãos que estudam na escola, tenho 1 irmã que estuda no $4^{\circ}$ Período, 1 que estuda na educação Infantil, 1 irmã que estuda aqui na sala, 1 irmã que estuda aqui, 1 no anexo da escola, 2 estudam na mesma escola (Grupo focal com educandos/as da Escola Esperança do Amanhã, novembro de 2017).

A maioria das crianças tem irmãos que estudam na escola e muitos deles vêm e voltam com os irmãos maiores.

Quando indagamos: $\mathrm{O}$ que gostam de fazer? Observe a resposta:

Brincar, estudar, ler, ajudar os colegas, viajar, jogar bola, mexer no celular, andar de bicicleta, andar a cavalo, atentar na sala (risos do educando), da escola, de fazer amigos na escola, do recreio, brincar de pega-pega, de roça, pegar passarinho, desenhar, escrever, jogar gude, gosto mais ou menos de estudar, de Deus. (Grupo focal com educandos/as da Escola Esperança do Amanhã, novembro de 2017).

Nesse momento, dois educandos falaram que trabalhavam e quando perguntamos em que trabalhavam, um disse: "Na feira e lavo carro". E indagamos: O que faz com o dinheiro? "Ajudo a minha mãe (olhos cheios de lágrimas)". O outro respondeu: "trabalho na eletrônica com o meu tio" e acrescentou: "dou o dinheiro para minha mãe quando meu pai deixa faltar as coisas". Para Arroyo (2015, p.28):
Corpos infantis e adolescentes consumidos no trabalho, na pobreza, na fome e na desnutrição, até nos castigos e massacres; crianças e adolescentes obrigados a trabalhos para sobrevivência e para colaborar com a renda familiar mínima, indo do trabalho à escola e da escola para trabalhos precarizados.

Os educandos ao relatarem que trabalham para ajudar a família, corroboram com a fala do autor que retrata o cotidiano de muitos adolescentes que moram em comunidades carentes.

Tivemos outros questionamentos com os educandos e o diálogo foi assim: Como vocês veem a escola? Ou o que acham da escola? E as narrativas foram essas:

Se a escola não existisse as pessoas não saberiam de nada, escola tem hora de brincar, de falar, tem a professora que ensina a respeitar o colega, se não tivesse a escola não iriamos aprender, a escrever, a ler, formar e ser alguém na vida, todos seriamos burros, na escola a gente aprender a obedecer, lugar de estudar, aprender tarefas, a escola é importante, a escola é boa, é interessante, gosto de vir para escola, fico chateada porque sábado não tem aula, é legal, porque se estuda, brinca, é bom vir para a escola por causa dos amigos, é boa, porque brinca no recreio, dá preguiça de vir para a escola, gosto de estudar, é importante, brinca no recreio jogo bola, pega-pega, o estudo é bom, não gosto de vir para a escola, pois fico cansado, tem dia que gosto e tem dia que não gosto, tem dia que tem muita atividade, acho bom a escola, gosto de brincar, porque a gente aprende, e se torna mais inteligente, estudar, gosto de vir para escola, dá pra desenhar, é importante estudar para aprender a ler, gosto de vir, gosto mais de aprender a ler, estudar para passar de ano, fico feliz quando venho para a escola, gosto de ler, aprende todas as coisas, tem recreio, faz tarefas, gosto da escola. (Grupo focal com educandos/as da Escola Esperança do Amanhã, novembro de 2017). 
Uma educanda acrescenta: "Minha mãe disse que a escola é muito importante, aprende a ler". Para Osório (2011 p.82):

Costuma-se dizer que a família educa e a escola ensina, ou seja, à família cabe oferecer à criança e ao adolescente a pauta ética para a vida em sociedade e a escola instruílo, para que possam fazer frente às exigências competitivas do mundo na luta pela sobrevivência.

Com base nesse pensamento, as famílias devem incentivar seus filhos a frequentarem a escola, pois é nesse espaço que ocorre a escolarização. E também necessita fazer parceria escola/família para que haja rendimento escolar satisfatório para ambas as partes.

Prosseguimos com o diálogo: O que vocês leem na escola e em casa? Qual leitura vocês gostam mais? E as respostas foram as seguintes:

Na escola leio o livro de português, matemática, geografia e história em casa leio gibi e revista, um dia eu brinco e outro leio sítio do picapau amarelo, na escola livros didáticos, em casa gibi, letreiros, Emília, bob esponja, livros de histórias em quadrinhos, livros de geografia Historinhas em quadrinhos, é importante ler para aprender escrever, leitura do livro da escola, livros da biblioteca, três porquinhos, branca de neve, o que a professora lê na sala de porque a história fica mais divertida, os três porquinhos que gosta de ler, o menino azul, pois foi o livro que tia lola deu, em cima daquela serra tem..., gosto da bela e a fera e dos três porquinhos, gosto do livro o gato de botas, a história da galinha pintadinha, turma da mônica, os livros da escola, mensagens do facebook, e whatsApp, livros de vez em quando, as placas na rua, livros didáticos, historinhas em quadrinhos, eu tento ler as placas e o que fica na parede, história em casa, de desenho em quadrinhos e livros, história que o povo conta, leio o que as pessoas estão falando, os livros da escola, chapeuzinho vermelho, o que mais gosto é o li- vro de português, as placas, os papeis que a professora dá, não sei ler, não gosto que leem para mim, as vezes manuseio livros.(Grupo focal com educandos/as da Escola Esperança do Amanhã, novembro de 2017).

Os educandos destacam a leitura dos livros de literatura infantil como os que eles mais leem e gostam, e em seguida vêm os livros didáticos que também fazem parte das leituras dos educandos. Mas, diante da fala de uma aluna de 10 anos que tem dificuldade na aquisição da leitura e escrita e que disse: "leio o que as pessoas estão falando". (Grupo focal com educandos/as da Escola Esperança do Amanhã, novembro de 2017). Para Cagliari (1993, p.21-22)

Uma criança que viu desde cedo sua casa cheia de livros, jornais, revistas, que ouviu histórias, que as pessoas gastando muito tempo lendo e escrevendo, que desde cedo brincou com lápis, papel, borracha e tinta, quando entra na escola, encontra uma continuação de seu modo de vida e acha muito natural e lógico o que nela se faz. Uma criança que nunca viu um livro em casa, nunca viu seus pais lendo jornal ou revista, que muito raramente viu alguém escrevendo, que jamais teve lápis e papel para brincar, ao entrar para a escola sabe que vai encontrar coisas lá, mas sua atitude em relação a isso é bem diferente da criança citada no parágrafo anterior. E a maneira como a escola trata da sua adaptação pode lhe trazer apreensões profundas até mesmo desilusões.

De acordo com o autor e com a fala da educanda, acreditamos que seja possível que ela aprenda a ler e escrever, levará um tempo maior para aquisições dos níveis de aprendizagem descritos por Ferreiro em suas pesquisas, por ter pouco contado com os diversos materiais exposto acima pelo autor.
Em seguida, perguntamos aos educandos: Com relação a escrita o que vocês mais gostam de escrever? E qual é a importância de aprender a ler e a escrever? $\mathrm{E}$ as respostas foram as seguintes:

Gosto de escrever história, escrever português, matemática, escrever sobre Jesus, copiar do livro, gosto de escrever história sobre qualquer coisa, gosto de escrever texto, história e textos, desenhar e escrever textos, não sei, escrever texto animal, texto sobre casa, história de desenho da TV, copiar a história no caderno, desenhar a história do chapeuzinho vermelho, escrever tudo, não gosto de desenhar, gosto de escrever, mas é difícil. (Grupo focal com educandos/as da Escola Esperança do Amanhã, novembro de 2017).

Diante desses dados, mesmo que a maioria dos educandos dessa turma ainda não dominam a leitura e a escrita convencional, eles demonstram gostar dessas práticas. Demos prosseguimentos com as indagações: Como vocês veem o que é ensinado pela professora sobre leitura e escrita? E obtivemos os seguintes relatos:

Acho bom, a professora ensina coisas novas e antigas, aprender a ler, a professora pede para escrever o ditado é bom, ler é importante, é bom para aprender, é ruim porque escreve muito, é importante, aprende a ler rápido, é bom, porque ensina a ler e a escrever e aprende rápido, porque a tia ensina, ela fica escrevendo texto, é fácil e ela ensina, eu gosto porque aprendo, gosto de estudar, aprendo muitas coisas, ela ensina a ler e a escrever, venho porque quero não gosto de ficar sozinho, ler e copiar, porque é importante, porque tem que vir para a escola, se não vir não aprende, aprende a ler e ensina a fazer a atividade, a gente aprende a ler e a escrever, faz tarefa e passar de ano.(Grupo focal com educandos/as da Escola Esperança do Amanhã, novembro de 2017). 
Com relação às atividades de leitura e escrita, os educandos foram categóricos ao responder que são boas essas práticas, pontuando que só por meio delas é que eles aprendem e ressaltam a importância, como disse esse interlocutor: "Ler e copiar, porque é importante, porque tem que vir para a escola, se não vir não aprende". (Grupo focal educandos/as da Escola Esperança do Amanhã, novembro de 2017). Demonstração da necessidade da escolarização. Com isso entendemos que as percepções dos educandos são positivas diante das atividades de leituras e escrita mobilizadas pela professora. Para Brasil (2012c, p.20):

\begin{abstract}
A escola precisa ser um ambiente que permita a ampliação das possibilidades de conhecimento das crianças em situações cuidadosamente planejadas, que favoreçam o uso da língua em diferentes situações ou contextos sociais, valorizando sua função diversificada e sua variedade de modos de falar. Para isso, a realização de um trabalho criativo e prazeroso que possibilite o desenvolvimento de habilidades comunicativas nos primeiros anos do Ensino Fundamental, por meio de diversas situações orais e escritas, deve ser uma preocupação constante do professor.
\end{abstract}

De todos os educandos que participaram do grupo focal, apenas dois manifestaram em seus depoimentos não gostar de vir à escola, falaram assim: o primeiro "Não gosto de vir para a escola, pois fico cansado". O segundo "Tem dia que gosto e tem dia que não gosto, tem dia que tem muita atividade". Certamente por que esses educandos trabalham no turno matutino e se sentem indispostos para irem à escola no outro turno. Questionamos aos educandos em que trabalham: "Na feira e lavo carro". Já o outro educando disse: "trabalho na eletrônica com o meu tio". Refletimos que esses educandos por trabalharem em um turno se sentem cansados no dia que tem muita atividade escolar.

Os demais educandos foram unânimes, destacaram a importância de vir a escola e das reações positivas quanto as práticas de leituras e escritas trabalhada pela docente e do vínculo criado

Isso nos remete que a prática de leitura em sala de aula, deve seguir uma sequência, para que o objetivo de ensino/aprendizagem em relação à leitura auxilie os educandos de forma gradual e constante. Todavia, destacamos que entendemos por sequência de prática de leitura, uma organização planejada, de forma metodológica e contextualizada, que propicie significados para os educandos.

Outro fator que certamente dificulta no processo de aprendizagem da leitura e escrita dos educandos, é a falta de apoio e ou acompanhamento de alguns dos seus responsáveis, talvez por não serem alfabetizados e por isso não poderem ajudar os filhos nas atividades, ou pelo contexto social em que vivem os educandos.

É de suma importância destacar que muitos condicionantes interferem na dinâmica escolar, para além dos muros da escola. Ademais, reforçamos a necessidade de políticas públicas educacionais e sociais para essa população que vive à margem da sociedade.

\section{CONSIDERAÇÕES FINAIS}

Este estudo é parte de uma pesquisa que tratou de analisar práticas de leitura e de escrita em uma turma do terceiro ano do ciclo de alfabetização, de uma escola pública de Guanambi, para compreender os fatores que interferem na aprendizagem dos educandos.

Os resultados apontam que a professora trabalha com práticas de leitura e escrita diversificadas e contextualizadas, as quais certamente influenciam de maneira significativa na aprendizagem dos educandos. Sua metodologia em sala de aula, parece atender a apreensão da alfabetização na perspectiva do letramento, levando em conta o objetivo de os educandos estarem alfabetizados até os 8 anos de idade, conforme destacado no caderno de apresentação do PNAIC e reconhecido pelo MEC.

Evidenciamos que a concepção de alfabetização e letramento da professora aproxima das discussões dos teóricos destacados nesta produção. A alfabetização e o letramento são processos significativos e indissociáveis no ensino/aprendizagem dos educandos, pois por meios destes processos a professora articula a mediação dos conhecimentos para que os educandos consigam levantar hipóteses sobre a leitura e escrita e posteriormente compreendam a função social dessas práticas. Queremos ressaltar a importância da professora com a formação dos educandos, pois esta demonstra comprometimento com a vida familiar e social de cada um deles.

Em relação ao PPP da escola os dados encontrados apontam para uma perspectiva de alfabetizar/letrando promovendo projetos de leitura com professores e educandos.

Constatamos que os educandos atribuem um valor positivo à leitura e à escrita, ressaltando a relevância destas práticas para o aprendizado e é imprescindível a importância que eles dão às práticas da professora destacando que sem essas não iriam aprender.

Contudo, os dados coletados sinalizam que existem fatores que podem interferir nesse processo de ensino/aprendizagem dos educandos em que alguns chegam no final do ciclo de alfabetização, sem estarem 
alfabetizados. Dentre os possíveis fatores, podemos destacar, a falta de apoio de alguns responsáveis, talvez por não serem alfabetizados e por isso não podem ajudar seus filhos nas atividades escolares, ou pelo contexto social em que esses educandos estão inseridos. Isso certamente dificulta o vínculo dos pais com a escola e com o estudo dos filhos, o que também pode refletir na aprendizagem dos educandos.

Em relação ao PNAIC, observamos que alguns dos educandos da turma pesquisada não se "encaixam" nesse contexto idealizado pelo programa, pois uma boa parte está em defasagem idade/série. Todavia, é preciso não desconsiderar os condicionantes sociais, políticos e estruturais que interferem na vida escolar do educando, pois o fenômeno educativo é muito complexo e extrapola os muros da escola.

Nesse sentido, esta pesquisa foi uma oportunidade valiosa para produzir conhecimentos sobre a temática, que certamente oferecerá contribuições significativas nas nossas práticas educativas, em possível atuação no ciclo de alfabetização. E ainda salientamos que a presente produção serviu para que mudássemos nosso olhar de pesquisadora/discentes para futuras docentes, tendo em vista os desafios que teremos que enfrentar e da necessidade de repensar a nossa prática enquanto docente.

É oportuno dizer, também, que a vivência com a professora interlocutora da nossa pesquisa, especificamente a sua preocupação e comprometimento com o contexto social em que estão inseridos os seus educandos, serviram de reflexão e de exemplo, para nos sensibilizarmos não só com o ensino aprendizagem em sala de aula, mas também com a vida extraescolar e com a necessidade material dos educandos.

Ademais, reconhecemos que a educação não é a panaceia dos problemas sociais, mas ela pode contribuir significativamente para a construção de uma sociedade menos desigual e mais inclusiva.

\section{REFERÊNCIAS}

ALVES, Francisco Cordeiro. Diário: um contributo para o desenvolvimento profissional dos professores e estudo dos seus dilemas. 2004. Disponível em: <

http://www.ipv.pt/millenium/milleniu m29/30.pdf > Acesso em 20/10/17.

ASSENCIO, Jéssica Gomes dos Santos. O PNAIC e a formação continuada dos alfabetizadores: uma análise a partir das contribuições para sua prática pedagógica. Porto Velho, 2016. Disponível em:

<http://www.meduc.unir.br/uploads/62 248421/arquivos/ DISSER-

TA_O__JESSICA_GOMES_DOS_ SAN-

TOS_ASSENCIO_701137680.pdf.. Acesso em 13/11/17.

ANDRADE, Ludmila. CORSINO, Patrícia. Critérios para a constituição de um acervo literário para as séries iniciais do ensino fundamental: um instrumento de avaliação do PNDE 2005. In_PAIVA. Aparecida. Literatura - saberes em movimento. Belo Horizonte. Ceale. Autêntica, 2007. p.88

ARROYO, Miguel. O direito à educação e a nona segregação social e racial - tempos insatisfatórios? 2015. Disponível em

<http://www.scielo.br/pdf/edur/v31n3/ 1982-6621-edur-31-03-00015.pdf > Acesso em 20/11/17.

BARBOSA, José Juvêncio. Alfabetização e leitura. São Paulo: Cortez, 1994. 2 ed. p.73.
Orientações curricu-

lares para ensino médio: linguagens, códigos e suas tecnologias. 1999. Disponível em <

http://portal.mec.gov.br/seb/arquivos/p df/book_volume_01_internet.pdf $>$. Acesso 20/10/17. p.154.

Programa de Forma-

ção Continuada de Professores Anos/Séries iniciais do Ensino Fundamental. Pró-Letramento. MEC/SEB. Brasília 2008. Disponível em: <

http://portal.mec.gov.br/index.php?opti on $=$ com_docman $\&$ view $=$ download $\&$ al ias $=6002$-fasciculo-

port\&category_slug=julho-2010pdf\&Itemid $=30192>$. Acesso 30/09/2017.

Ministério da Educação. Manual do pacto: Pacto pela Alfabetização na Idade Certa: o Brasil do futuro com o começo que ele merece. Brasília, DF, 2012a.

.Pacto Nacional pela Alfabetização na Idade Certa. Obras Complementares. MEC/SEB. Brasília 2012b. Disponível em:

<http://portal.mec.gov.br/index.php?op tion $=$ com_docman $\&$ view $=$ download $\&$ alias $=12696$-acervoscomplementares2013-site-pdf\&category_slug=marco2013-pdf\&Itemid=30192 > . Acesso em $15 / 11 / 17$.

.Secretaria de Educação

Básica. Acervos complementares: alfabetização e letramento nas diferentes áreas do conhecimento / Ministério da Educação, Secretaria de Educação Básica. - Brasília: A Secretaria, 2012c.

Pacto Nacional pela Alfabetização na Idade Certa. Caderno de Apresentação. MEC/SEB. Brasília 2015. Disponível em: < http://pacto.mec.gov.br/o-pacto > . Acesso em 10/09/17.

BRASIL, Ministério da Educação. Base Nacional Comum Curricular. 3. versão, Brasília, 2017. 
CAGLIARI, Luiz Carlos. Alfabetização e linguística. 5 ed. São Paulo, Scipione, 1993. p.148 -155

FERREIRO, Emília. TEBEROSKY, Ana. Psicogênese da língua escrita. Tradução: Diana Myriam Lichtenstein. Liana di Marco. Mário Corso. 4 ed. Porto Alegre: Artes Médicas, 1991. P.183-213.

FERREIRO, Emília. Reflexões sobre alfabetização. 26 ed. São Paulo: Cortez, 2011. p.14.

FREITAS, Escola Municipal Maria Regina. Projeto Político Pedagógico 2015/2016. Guanambi, BA. p.11/39.

GATTI. Angelina Bernadette. Grupo focal na pesquisa em ciências sociais e humanas. Brasília: Liber livro, 2005. Disponível em:

<https://docslide.com.br/download/lin k/gatti-bernardete-angelina-grupofocal-na-pesquisa-em-ciencia-1> . Acesso em: 20/11/17.

GERALDI, João Wanderley. Alfabetização e Letramento perguntas de um alfabetizado que lê. 2010. Disponível em: <

http://www.antigomoodle.ufba.br/file. php/2/Alfabetiza_o_Letramento/Letra men-

to_e_Alfabetiza_o_Perguntas_de_um_ alfabetizado_que_1_.doc $>$. Acesso em 27/09/17.

IBGE - Dados de pesquisa sobre as famílias brasileiras. Disponível em < http://g1.globo.com/brasil/noticia/2012 /10/familias- chefiadas-por-mulheressao-373-do-total-no-pais-apontaibge.html>. Acesso em 20/11/17.

KLEIMAN, Ângela. Professores e agentes de letramento: identidade e posicionamento social. Filol. lingüíst. port., n. 8, p. 409-424, 2006. Disponível em: <http://www.revistas.usp.br/ flp/article/view/59763/62872 >. Acesso em 27/07/2017.

MACHADO, Vânia Regina Barbosa Flauzino. Pacto Nacional pela Alfabetização na Idade Certa (PNAIC): Conquistas e Desafios. Maringá,
2016. Disponível em: <

http://www.ppe.uem.br/dissertacoes/20 16/2016\%20-

$\% 20$ Vania\%20Regina\%20Barbosa\%2

0 Flauzino\%20Machado.pdf $>$. Acesso em 13/11/17.

MORTATTI, Maria Rosário Longo.

Educação e Letramento. [Livro de eletrônico]. São Paulo: Editora UNESP, 2004. Paradidáticos collection; Educação series. Disponível em: <https://play.google.com/books/rea der?id=M30EAwAAQBAJ\&printsec $=$ frontco-

ver\&output=reader\&hl=pt_BR\&pg $=\mathrm{G}$ BS.PA4 >. Acesso em: 27/07/2017.

OSORIO, Luiz Carlos. MCSIL. James. Família hoje. E-book. Porto Alegre. Editora Artes Médicas. 2011. Disponível em:

<https://www.amazon.com.br/FAM\% C3\%8DLIA-HOJE-Luiz-Carlos-

Os\%C3\%B3rio ebo-

$\mathrm{ok} / \mathrm{do} / \mathrm{B} 0069 \mathrm{CGLHY} / \mathrm{ref} .=\mathrm{sr}$-1_1?ie= UTF8\&qid $=1511587322 \& s r$

$=81 \&$ keywords $=$ familia + hoje $>$. Aces so em $20 / 11 / 17$.

RIZZO, Gilda Menezes. LEGEY, Eliane Prista. Fundamentos e metodologia da alfabetização: método natural. Rio de Janeiro: Francisco Alves, 1990.

SANTIAGO, Luciane Teresinha Munhoz. As influências do PNAIC na dinâmica do processo de Alfabetização. Canoas, 2015. Disponível em: < https://unilasalle.edu.br/public/media/4 /files/Educa\%C3\%A7\%C3\%A3o/Diss er-

ta\%C3\%A7\%C3\%B5es/(Disserta\%C3 $\%$ A7\% $3 \%$ A30\%20-

Luciane_2015).pdf >. Acesso em 13/11/17.

SCHUVETER. Márcia Aparecida. O Processo de alfabetização e o projeto político -pedagógico em escolas de ensino fundamental. Rio Claro, 2009. Disponível em:

<https://repositorio.unesp.br/handle/11 449/90055>. Acesso em 13/11/17.
SOARES, Magda. As muitas facetas da alfabetização. Cad. Pesq., São Paulo: (52): 19-24, fev, 1985. Disponível em: $<$ http://publicacoes.fcc.org.br/ojs/inde x.php/cp/article/view/1358/135>.

Acesso em 20/07/17

Centro de Alfabetização.

Leitura e Escrita. Faculdade de Educação/UFMG. Belo Horizonte, maio/junho de 2007 - ano 3 n $^{\circ} 10$.

Disponível em: $\leq$

http://www.ceale.fae.

ufmg.br/app/webroot/files/uploads/JL A/2007_JLA10.pdf\#page $=3>$. Acesso em 25/09/17.

Alfabetização e Letra-

mento: caminhos e descaminhos. Caderno de formação: formação de professores didática de conteúdos. Unesp - São Paulo: Cultura Acadêmica. 2011. V.2, p.96. Disponível em: < https://acervodigital.unesp.br/bitstream /123456789/40142/1/01d 16t07.pdf >. Acesso em 20/07/17.

Letramento: um tema em três gêneros. São Paulo: Autêntica, 1999. Disponível em: <

https://oportuguesdobrasil.files.wordpr ess.com/2015/02/4soares_letramento.p df > Acesso em 20/11/17.

SILVA, Ademar. Alfabetização: a escrita espontânea. 2 ed. São Paulo: Contexto, 1994.

\section{SOLÉ, Isabel. Estratégias de leitura.} [recurso eletrônico]. 6 ed. Porto Alegre. Penso. 2014. e.PUB. Disponível em: <

https://ler.amazon.com.br/?asin=B016 90SVG4 >. Acesso em 09/10/2017.

WEISZ. Telma. SANCHEZ, Ana. O diálogo entre o ensino e a aprendizagem. 2 ed. São Paulo: Ática, 2009. 